Article

\title{
Investigating the Impact Factors of the Logistics Service Supply Chain for Sustainable Performance: Focused on Integrators
}

\author{
Yingjie Ju ${ }^{1}$, Yue Wang ${ }^{1, *}$, Ye Cheng ${ }^{2}$ and Jun Jia ${ }^{1}$ \\ 1 School of Business, University of Jinan, Jinan 250002, China; 20172120809@mail.ujn.edu.cn (Y.J.); \\ se_jiaj@ujn.edu.cn (J.J.) \\ 2 School of Management Engineering, Shandong Jianzhu University, Jinan 250101, China; \\ 15966699365@163.com \\ * Correspondence: se_wangy@ujn.edu.cn
}

Received: 11 December 2018; Accepted: 18 January 2019; Published: 21 January 2019

check for updates

\begin{abstract}
The overall scale of China's logistics industry is growing rapidly, and the environment and conditions for its development are constantly improving, which lays a solid foundation for further accelerating the development of the logistics industry. However, logistics services are characterized by subordination, immediacy, demand volatility, and substitutability. Low-level integrated management of logistics services seriously hinders the development of the logistics service supply chain (LSSC) for sustainable performance. Many studies have been limited to the performance evaluation of LSSCs, and the factors affecting LSSC performance have generally been ignored. This study focuses on integrated LSSC s by using an integrator's opportunistic behavior as the entry point of research and investigates the factors that affect the sustainability of LSSC performance. On the basis of relevant theories, a model for a hypothesis is constructed and eight hypotheses are subsequently proposed. Moreover, 271 survey responses from functional logistics service providers (research object) are utilized to develop a structural equation model for empirical research. Findings show that integrators with opportunistic behavior inhibit the information-sharing behavior of supply chain members. Consequently, the integration capability and agility of LSSCs are reduced, which affects the overall performance of LSSCs. The findings of this study can provide management insights into the behaviors of supply chain members and governments.
\end{abstract}

Keywords: opportunistic behavior; integrated logistics; logistics service supply chain; sustainable performance

\section{Introduction}

The logistics industry, as an important part of the service industry, has received considerable attention in recent years in the industrial and academic fields [1]. China's medium- and long-term Plan for Logistics Industry Development (2014-2020) emphasizes the comprehensive role of the logistics industry in the service industry. Logistics integrates multiple industries such as transportation, warehousing, freight forwarding and information [2]. The logistics industry is also regarded as a basic and strategic industry because it supports national economic development [3]. With the continuous improvement of this industry, its service provision has attained supply chain characteristics. Logistics service supply chain (LSSC) is a special type of supply chain within the service supply chain in which logistics service integrators serve as the core players. LSSCs provide flexible services to ensure effective logistics operations [4]. The LSSC structure mainly comprises functional logistics service providers, logistics service integrators and manufacturing and retail companies [5]. Modern logistics has developed towards green, sustainable, and integrated. 
China's logistics industry has developed rapidly in recent years. However, in comparison with the level of logistics advancement in developed countries, China's logistics industry is still in the midst of transitioning from the development stage to the maturity stage. On the one hand, the pace of asset reorganization and resource integration of logistics enterprises has accelerated [6], and numerous logistics enterprises with diversified ownership, networked services, and modernized management have formed [7]. On the other hand, the ratio of the total cost of social logistics to GDP has gradually decreased, and the trend of transformation and upgrading of the logistics industry is evident. Furthermore, the quality and efficiency of logistics operations have improved [8]. The ratio of the total social logistics expenses to GDP has constantly been much higher in China than in developed countries. In 2017, the ratio was $14.9 \%$ in China and less than $10 \%$ in the United States, Japan, and Germany. Therefore, China's logistics industry still has a large space for advancement. With the strengthening of China's awareness on environmental protection and the concept of sustainable development, upstream and downstream enterprises of LSSCs are focused on social and environmental issues as important factors affecting the development of enterprises $[9,10]$. Under the pressure of increasingly fierce competition, enterprises are paying increasing attention to reducing related costs to achieve optimal cost [11], quality [12], price, logistics, and customer satisfaction [13], as well as realizing the sustainable development of a supply chain. However, China's logistics service market is volatile and uncertain. Traditional logistics enterprises are small and scattered, thus requiring integration and innovation. Major strategic issues in market environment change and technological innovation constantly challenge enterprises. Enterprises are also facing continuous difficulties in supporting sustainable competitive advantages by relying only on internal resources and relations. Enterprises must enhance their ability to quickly organize supply chains and improve the sustainable performance of supply chains $[14,15]$. Therefore, it is of theoretical and practical significance to study the implementation methods of enterprise strategy in order to improve the sustainable performance of supply chain and maintain the long-term development of enterprises.

Logistics services are generally concentrated on urban logistics development. Logistics service integrators, as the core players of enterprise activities, play decisive roles in supply chain operations. They serve as intermediaries and bridges between the demand side and the service side of logistics [16]. In actual operations, owing to information asymmetry and limited rationality, integrators can freely choose whether to behave opportunistically (to improve the income of their respective enterprises) or share information (to solve problems of information silos) [17]. According to extant research on product supply chains, the opportunistic behavior of suppliers negatively affects the content and quality of information sharing (IS). Then, according to the research on supply-and-demand interactions, demand uncertainty reduces opportunism, whereas supply uncertainty increases opportunism [18]. In addition, some scholars believe that supply-demand interaction as a prerequisite will significantly affect the sustainability of supply chain performance. Technology (e.g., IT capabilities) and relationship (e.g., information sharing, trust, and operational collaboration) factors are prerequisites for promoting enterprise performance growth in an agile supply chain. Information sharing affects enterprise performance through the intermediary role of supply chain agility, which is also regulated by environmental dynamics and information system capabilities [19]. Supply chain agility and integration capabilities are equally important topics in the research on LSSC performance [20]. However, when integrators take opportunistic actions, it is not clear what impact they have on supply chain agility and integration capabilities. Because of the immediate benefits of opportunism, integrators may temporarily improve their own interests [21]. How will an integrator's opportunistic behavior (SO) affect LSSC performance in the long run? Is the path of influence direct or indirect? The answers to these questions can help explain the sustainable development of LSSCs.

The combined results of previous research have reported three relevant shortcomings. Firstly, in terms of research objects, most studies mainly focus on the product supply chain and ignore the factors that affect the sustainability of LSSC performance [22-24]. An LSSC differs from the general product supply chain. Logistics service market is highly volatile and vulnerable to human factors. We need to 
focus on the behavior preferences of core participants (i.e., integrators). Secondly, in the process of investigating the impact of behavior on performance, previous research ignored the joint role of supply chain integration and agility $[25,26]$. Finally, from the perspective of research, the existing research on the factors affecting the sustainable performance of supply chain is relatively scattered $[27,28]$, lacking a unified and empirical verification of the normative model [29].

In order to supplement the research gap and take into account the popularity of logistics services in China, this study first analyzed the opportunistic behavior of integrators, and then systematically studied its impact on the sustainable performance of LSSCs. The paper is organized as follows. Section 1 introduces the background and sustainability of the research issues. Section 2 reviews relevant literature and proposes a research model with developed hypotheses. Section 3 presents the research methodology. Section 4 discusses the results of the analysis. Sections 5 and 6 conclude the study with a discussion of the results, implications and limitations of the study and future research needs. China, as a populous country, is known for its huge demand for logistics services. With accelerating urbanization, the original operational mode of China's urban logistics has gradually but intensively reformed and developed. The findings from this research can help integrators improve their behavior, establish lasting partnerships with other enterprises and promote innovations in traditional logistics operations, thereby contributing to the sustainable development of LSSCs.

\section{Theoretical Basis and Research Hypothesis}

\subsection{Opportunistic Behavior of Integrators, Information Sharing, and Agility of LSSCs}

According to the transaction cost theory, opportunistic behavior can be described as an enterprise's speculative behavior for its own benefit. Suppose that integrators and service providers are in an information-incompatible state [30], integrators can easily block messages and generate speculative behavior for their own benefit. Once discovered by partners, this opportunistic behavior will have a far-reaching impact on the relationship between the two sides, which will inhibit information sharing [31]. The rapid response of supply chain to demand information will slow down and affect the flexibility of supply chain.

Existing descriptions on agility originate from the concept of 'flexible manufacturing system' in the 1990s. Agility refers to the ability of an organization to use its knowledge and other partners to ensure its continued profitability when facing a volatile market environment [32]. The traditional research on agility is mainly aimed at the manufacturing industry or a single enterprise. However, as the industry changes, most enterprises exist in the form of supply chain members who need to rely on the strength of upstream and downstream enterprises to cope jointly with market changes.

LSSCs, as a special type of supply chain, must respond rapidly to market changes to optimize the overall process of their logistics services and improve their agility. Considering that an integrator is regarded as the leader of the entire service supply chain, its opportunistic and information-sharing behaviors can likewise considerably impact the agility of LSSCs (SCA) [33]. In addition, the ability of trust and integrity of supply chain enterprises can improve the communication between organizations, thus promoting stable cooperation within the supply chain and improving its flexibility. By contrast, opportunistic behavior inhibits trust [34]. Blome [35] argues that information sharing amongst members positively affects the flexibility of the supply chain; however, its impact on the agility of the supply chain is not yet conclusive. Research findings on the resources acquired by LSSCs indicate that integrators must collect large amounts of market and customer information, which is an important method for logistics service providers to obtain market information [36]. The timely knowledge and information sharing of integrators promote optimization and coordination of the entire supply chain [37], which then enables the enterprises to rationally decide and improve the decision making and agility of LSSCs. From the perspective of upstream and downstream organizational relationships, the opportunistic behavior of integrators inhibits communication, cooperation and coordination with suppliers and hinders knowledge and information sharing amongst enterprises, 
thereby affecting the agility of LSSCs. From the perspective of energy efficiency, improving energy efficiency and solving the problem of energy dispatch and distribution can effectively improve the sustainability and agility of supply chains [38]. On the basis of the above analysis, this research proposes the following assumptions:

Hypothesis 1 (H1). The opportunistic behavior of integrators significantly and negatively impacts information sharing.

Hypothesis 2 (H2). The opportunistic behavior of integrators significantly and negatively impacts the agility of LSSCs.

Hypothesis 3 (H3). Information sharing significantly and positively impacts the agility of LSSCs.

\subsection{Opportunistic Behavior of Integrators, Information Sharing, and Integration Capabilities of LSSCS}

The 21st century is the era of service economy, and a rising trend in service provision and outsourcing in the logistics industry is observed [39]. As the overall scale of service industry continues to expand, we need to pay attention to the construction of logistics service brand. At present, the research on LSSCs mainly focuses on integration and coordination [40]. However, from the practical viewpoint, most enterprises do not fully understand LSSCs, how they affect logistics and how partnerships within LSSCs differ from those of supply chains [5,41-43].

In LSSCs, integrators rely on supply-and-demand relationships, particularly the market services between logistics service providers and customers [44]. The management activities of integrators generally include forecasting [45], planning [46], controlling [47], risk avoidance [48], and performance research $[33,49,50]$. The efficient operation of an LSSC requires good multi-party working relationships across different organizational levels. When opportunistic behavior manifests [28], the working relationships of the different departments loosen and the willingness to cooperate across organizations is reduced, thus affecting the integration capabilities of LSSCs (SCI) [51]. Organizational integration tightens the functional synergies of organizational processes and improves organizational structures, thereby helping ensure the sustainability of LSSCs. The sharing of logistics capabilities (information, demand, supply, cooperation, and coordination) between upstream and downstream partners, particularly through effective logistics integration, strongly affects the resilience of the supply chain [6]. Thus, the following assumptions are made:

Hypothesis 4 (H4). The opportunistic behavior of integrators significantly and negatively impacts the integration capabilities of LSSCS.

Hypothesis 5 (H5). Information sharing significantly and positively impacts the integration capabilities of LSSCS.

\subsection{Agility and Integration Capabilities of LSSCS}

In LSSCs, integration leads to the resource-sharing of integrators and service providers [52]. This scenario breaks down work barriers and promotes the exchange of information and resources across the supply chain. Supply chain integration also enhances the stability and reliability of partners and the overall competitive advantage of the LSSC. Agile LSSC means that in the context of market volatility, the strategic vision of supply chain members has been strengthened [53], that is, agility is the basis of process reorganization based on communication (access to information) and supply chain integration. Leading enterprises can accurately capture market demand by connecting upstream and downstream information. They can operate independently, respond flexibly to market changes and remain competitive. The concepts of 'contradiction' and 'transformation' between the integration and agility of supply chains can effectively achieve coordination by utilizing a development framework and 
dynamically adjusting the model via information systems [54]. Moreover, the integration capabilities of supply chain enhance the flexibility of its member enterprises and helps to realize agile supply chain [55]. Strategies for supply chain agility require high-level supply chain integration, both internally and externally. Therefore, the following assumption is made:

Hypothesis 6 (H6). The integration capabilities of an LSSC significantly and positively affect the agility of the LSSC.

\subsection{Agility, Integration Capabilities and Performance of LSSCs}

Some scholars have conducted research on the agility and integration capabilities of supply chains because both aspects play important roles in improving the competitiveness of the supply chain market. However, the paths of agility and integration capabilities of LSSCs towards organizational performance remain unclear. Improving the agility of supply chains significantly and positively impacts enterprise performance and plays a partial intermediary role between supply chain management practices and enterprise performance [22]. This finding provides an important guide for companies in implementing supply chain management practices and improving supply chain agility.

Amongst manufacturing companies, the integration (internal integration, supplier integration, and customer integration) of product supply chains results in a medium-intensity positive impact on organizational performance [56]. The relationship between integration and performance is regulated by enterprise size, market environment and national culture. Appropriate integration strategies can reduce resource waste and minimize recurring expenditures in the supply chain, which has a positive impact on operational and environmental performance. Moreover, through integration, LSSC members can acquire capabilities, resources, knowledge, information and relationships, reduce costs and avoid operational risks [57]. When an LSSC develops highly agile capabilities, its enterprises can respond rapidly to market changes [58], thereby effectively shortening service delivery cycles and increasing the frequency of service updates. Consequently, by fully identifying risks and opportunities, enterprises can seize opportunities and gain competitive advantage, which then improve the performance of the LSSC. Thus, the following assumptions are made:

Hypothesis 7 (H7). The agility of an LSSC significantly and positively impacts the performance of the LSSC.

Hypothesis 8 (H8). The integration capabilities of an LSSC significantly and positively impact the performance of the LSSC.

From the above assumptions, this study constructs a basic conceptual model to analyze comprehensively the indirect impact of various factors on the performance of LSSCs (Figure 1).

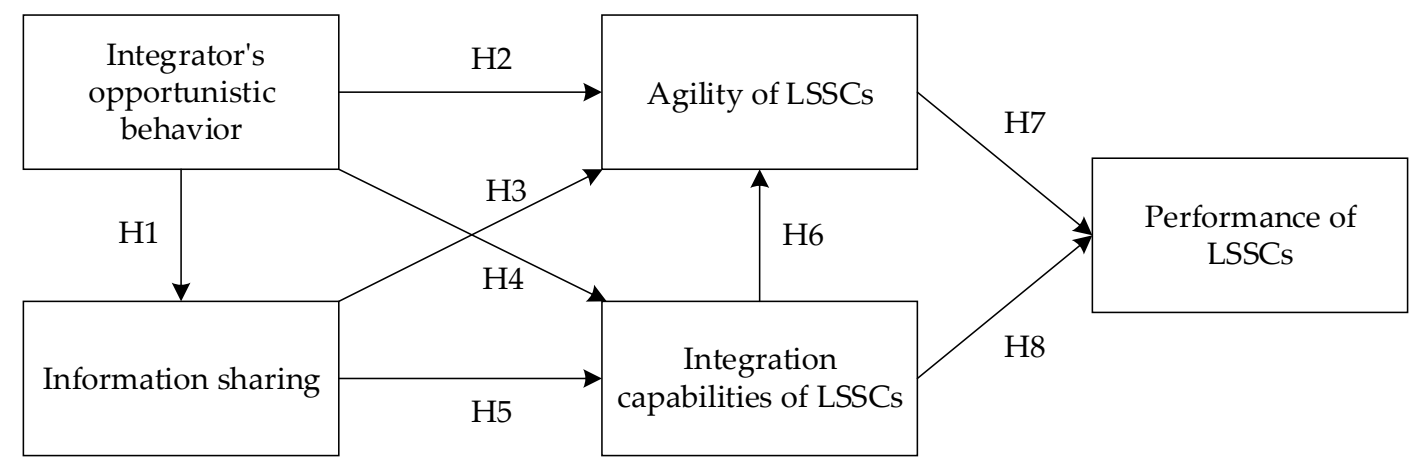

Figure 1. Conceptual model. LSSCs: logistics service supply chain. 


\section{Research Methodology}

\subsection{Sample Selection and Data Collection}

A survey was conducted in Shandong Province and radiated throughout Eastern China. Shandong Province is a populous region with a huge demand for the logistics industry. This area represents the status quo of the development of China's LSSCs. The research object of this study is the functional logistics service providers in LSSCs. The research work covered five months, from April 2018 to September 2018. Two main approaches were adopted for the survey. (1) The first channel was an online survey that was sent to the link of the online survey through social media channels (e.g., QQ, email and WeChat) to logistics practitioners. (2) The second channel was a field survey conducted by four trained investigators. Potential respondents were informed regarding the details on the aim of the survey and the concept of LSSCs. They were chosen from the logistics park in Jinan City, which is the capital of Shandong Province. The respondents completed the written questionnaires after they agreed to participate in this research. A total of 400 survey questionnaires were distributed. Of the 312 returned questionnaires, 271 were valid. Hence, the effective recovery rate was $68 \%$.

\subsection{Design of the Questionnaire}

To ensure the reliability of the survey results, the items used in the questionnaire were adopted from mature measurement scales previously applied at home and abroad. Some scales were adjusted to align the items with the research purpose. A five-point Likert scale was used to evaluate the survey variables and represent the perceived agreements between the contents of a measurement item and the actual situation (strongly disagree $=1$, disagree $=2$, neutral $=3$, agree $=4$, strongly agree $=5$ ).

This study refers to the previous literature to operationalize the items for each construct. According to the literature of Anderson [59] and Rokkan et al. [60], we designed the project of integrator's opportunistic behavior and measured it through four indicators: commitment [59], informal agreement [60], contract loophole [60], and accident [60]. In terms of information sharing, we fully consider the running path of services in the supply chain. Referring to the literature of Zhou [61] and Ye et al. [62], we selected four items:-capability [62], planning [61], information [61], and prediction [62] - for measurement. The agility of LSSCs is a formative construct, which comprises of three dimensions regarding customization level [63], service agility [63] and product development cycle [63]. Referring to the research results of Flynn [64], the integration capabilities of LSSCs was measured. We have designed four items in total, namely, strategic cooperation [64], cross-functional team [64], service process [64], and information network [64]. Flynn [64], Jia [65], and Feng et al. [66] constructed evaluation indicators on performance of LSSCs, measured this performance from the two dimensions of financial performance (SCP-EC) and service capabilities (SCP-SC). Financial performance includes return on investment [64], growth in profit [64], asset-liability ratio [65], and market share [64], while service capability includes customer satisfaction [66], cooperative trust [66], new product development [64], and high-level service [64]. The items were translated into Chinese and a double check was conducted by Ph.D. students to guarantee the translation accuracy. Several items were modified to better adapt to the research context. Table 1 shows the variable measurement items of the survey used in this study. 
Table 1. Measurement scales in the formal questionnaire.

\begin{tabular}{|c|c|}
\hline Constructs and Measuring Item & Sources \\
\hline $\begin{array}{l}\text { Integrator's opportunistic behavior } \\
\text { OB1: Integrators made a commitment in a few things but later did not honor such } \\
\text { commitment for some reason. } \\
\text { OB2: Integrators may violate our informal agreements for maximum benefit. } \\
\text { OB3: Integrators increase their revenue by exploiting contract loopholes. } \\
\text { OB4: Integrators may force us to make concessions with unexpected events. }\end{array}$ & {$[59,60]$} \\
\hline $\begin{array}{l}\text { Information sharing } \\
\text { IS1: Members of the LSSC share information regarding our service capabilities. } \\
\text { IS2: Members of the LSSC share planning information on related services. } \\
\text { IS3: Members of the LSSC share the demand forecast information for related services. } \\
\text { IS4: Members of the LSSC work with us to forecast service demand. }\end{array}$ & {$[61,62]$} \\
\hline $\begin{array}{l}\text { Agility of LSSCs } \\
\text { SCA1: Our supply chain can improve the level of service customisation. } \\
\text { SCA2: Our supply chain can increase the speed of improving customer service levels. } \\
\text { SCA3: Our supply chain can compress the development cycle of service products. }\end{array}$ & [63] \\
\hline $\begin{array}{l}\text { Integration capabilities of LSSCs } \\
\text { SCI1: LSSC partners have established strategic partnerships. } \\
\text { SCI2: We applied cross-functional teams in the process of service process optimization. } \\
\text { SCI3: Integrators help us improve our service processes to better meet customer needs. } \\
\text { SCI4: We contact our key customers via the information network to obtain feedback. }\end{array}$ & {$[64]$} \\
\hline $\begin{array}{l}\text { Performance of LSSCs-financial performance } \\
\text { EC1: Our return on investment is higher than that of our competitors. } \\
\text { EC2: Our profit growth rate is higher than that of our competitors. } \\
\text { EC3: We have lower asset-liability ratio than that of our competitors. } \\
\text { EC4: Our market share is growing faster than that of our competitors. }\end{array}$ & {$[64,65]$} \\
\hline $\begin{array}{l}\text { Performance of LSSCs—-service capabilities } \\
\text { SC1: Customers are very satisfied with the logistics services we provide. } \\
\text { SC2: Partners have high trust and can communicate with timeliness and accuracy. } \\
\text { SC3: Our logistics service delivers high reliability and a high degree of specialization. } \\
\text { SC4: We can promptly adopt new technologies and develop new services. }\end{array}$ & {$[64,66]$} \\
\hline
\end{tabular}

\subsection{Reliability and Validity Test}

The validity and reliability of the survey variables were initially tested before the hypothesis theory mentioned in previous work was verified. Firstly, in accordance with the work of Thompson et al. [67], we conducted confirmatory factor analysis (CFA) on all variables of the model, adjusted the model according to the adjustment index and factor load, and deleted items that that did not meet the requirements of the model. The results of data analysis showed that the survey indicators, which were adopted from mature measurement scales, have good content validity. The Cronbach's $\alpha$ used in this study for the dimensions of each construct is higher than the critical value of 0.7 , as proposed by Nunnally [68], indicating that the internal consistency of the scale used in this research is good. Thus, validity and reliability are both satisfied. Moreover, the factor load of each dimension in each construct is greater than 0.4, indicating that the measurement scale satisfies the 1-D requirement. As shown in Table 2, the composite reliability (CR) of all dimensions is greater than 0.6 , indicating that the intrinsic quality of the model is ideal [69]. With regard to the average variance extracted (AVE), all measured dimensions are greater than 0.5 , indicating that aggregation validity is satisfied [69]. The AVE method was performed to assess whether the AVE in the construct dimension is greater than the decision coefficient of other dimensions and subsequently determine the discriminant validity of the scale. As shown in Table 3, the model used in this study has good discriminant validity. 
Table 2. Descriptive statistics, factor loading, Cronbach's $\alpha$, composite reliability (CR) and average variance extracted (AVE) for each variable.

\begin{tabular}{|c|c|c|c|c|c|}
\hline Construct & Item & Standardised Factor Loading & Cronbach's $\alpha$ & CR & AVE \\
\hline \multirow{4}{*}{$\begin{array}{c}\text { Integrator's } \\
\text { opportunistic } \\
\text { behavior (SO) }\end{array}$} & SO1 & 0.76 & \multirow{4}{*}{0.852} & \multirow{4}{*}{0.862} & \multirow{4}{*}{0.615} \\
\hline & $\mathrm{SO} 2$ & 0.97 & & & \\
\hline & $\mathrm{SO} 3$ & 0.63 & & & \\
\hline & $\mathrm{SO} 4$ & 0.74 & & & \\
\hline \multirow{4}{*}{$\begin{array}{l}\text { Information } \\
\text { sharing (IS) }\end{array}$} & IS1 & 0.81 & \multirow{4}{*}{0.888} & \multirow{4}{*}{0.888} & \multirow{4}{*}{0.665} \\
\hline & IS2 & 0.80 & & & \\
\hline & IS3 & 0.87 & & & \\
\hline & IS4 & 0.78 & & & \\
\hline \multirow{3}{*}{$\begin{array}{c}\text { Agility of } \\
\text { LSSCs (SCA) }\end{array}$} & SCA1 & 0.92 & \multirow{3}{*}{0.924} & \multirow{3}{*}{0.925} & \multirow{3}{*}{0.804} \\
\hline & SCA2 & 0.91 & & & \\
\hline & SCA3 & 0.86 & & & \\
\hline \multirow{4}{*}{$\begin{array}{l}\text { Integration } \\
\text { capabilities of } \\
\text { LSSCs (SCI) }\end{array}$} & SCI1 & 0.77 & \multirow{4}{*}{0.825} & \multirow{4}{*}{0.828} & \multirow{4}{*}{0.550} \\
\hline & SCI2 & 0.82 & & & \\
\hline & $\mathrm{SCI} 3$ & 0.75 & & & \\
\hline & SCI4 & 0.61 & & & \\
\hline Performance of & EC1 & 0.74 & \multirow{4}{*}{0.812} & \multirow{4}{*}{0.813} & \multirow{4}{*}{0.522} \\
\hline \multirow{3}{*}{$\begin{array}{l}\text { LSSCs-financial } \\
\text { performance } \\
\text { (SCP-EC) }\end{array}$} & EC2 & 0.74 & & & \\
\hline & EC3 & 0.69 & & & \\
\hline & EC4 & 0.72 & & & \\
\hline Performance of & SC1 & 0.76 & \multirow{4}{*}{0.845} & \multirow{4}{*}{0.843} & \multirow{4}{*}{0.574} \\
\hline \multirow{3}{*}{$\begin{array}{c}\text { LSSCs-service } \\
\text { capabilities } \\
\text { (SCP-SC) }\end{array}$} & SC2 & 0.73 & & & \\
\hline & SC3 & 0.79 & & & \\
\hline & SC4 & 0.75 & & & \\
\hline
\end{tabular}

Table 3. Correlation between constructs.

\begin{tabular}{cccccc}
\hline & SO & IS & SCA & SCI & SCP \\
\hline SO & 0.785 & & & & \\
IS & -0.347 & 0.816 & & & \\
SCA & -0.621 & 0.277 & 0.742 & & \\
SCI & -0.228 & -0.085 & 0.734 & 0.897 & \\
SCP & 0.051 & -0.034 & 0.712 & 0.482 & 0.723 \\
\hline
\end{tabular}

\section{Structural Equation Model and Path Test}

\subsection{Goodness-of-Fit Statistics}

This study used AMOS 24.0 to analyze the influence of integrator's opportunistic behavior, information sharing, agility and integration capabilities of LSSCs on LSSC performance. In reference to Jackson's work [70], we selected Chi-square/degree of freedom, goodness-of-fit index (GFI), root mean square residual (RMR), adjusted goodness-of-fit index (AGFI), normed fit index (NFI), comparative fit index (CFI) and root mean square error of approximation (RMSEA) for the testing. The results of the confirmatory fitness test are shown in Table 4 . The indicators meet the requirements, except for AGFI which has a value lower than that of the standard. Thus, the model has good fit.

Table 4. Measurement model fit indices. Goodness-of-fit index (GFI), root mean square residual (RMR), adjusted goodness-of-fit index (AGFI), normed fit index (NFI), comparative fit index (CFI) and root mean square error of approximation (RMSEA).

\begin{tabular}{cccccccccc}
\hline Fit Indices & NC $(\boldsymbol{\chi} \mathbf{2} / \mathbf{d f})$ & GFI & AGFI & NFI & CFI & RMR & RESEA & PGFI & PNFI \\
\hline Indicators & 1.424 & 0.906 & 0.881 & 0.931 & 0.978 & 0.049 & 0.04 & 0.716 & 0.802 \\
Criteria & $<3$ & $>0.9$ & $>0.9$ & $>0.9$ & $>0.9$ & $<0.05$ & $<0.05$ & $>0.05$ & $>0.05$ \\
\hline
\end{tabular}




\subsection{Direct Effect Path Test}

After the overall analysis was performed using AMOS 24.0, the structural equation model (Figure 2) and the path coefficient test results (Table 5) were obtained. As shown in Figure 2 and Table 5, eight paths exist for the five latent variables. However, seven paths were significant at the $p<0.05$ level. The opportunistic behavior of integrators significantly affected the information sharing $\left(\beta=-0.348, \mathrm{t}=-5.082, p={ }^{* * *}\right)$, integration abilities $\left(\beta=-0.609, \mathrm{t}=-7.806, p={ }^{* * *}\right)$ and agility of LSSCs $\left(\beta=-0.244, \mathrm{t}=-4.164, p={ }^{* * *}\right)$. Thus, H1, H2, and H4 were supported. Information sharing significantly influenced the integration ability of LSSCs $\left(\beta=0.263, \mathrm{t}=4.345, p={ }^{* * *}\right)$. Thus, H5 was supported. Moreover, integration abilities $\left(\beta=0.646, t=5.600, p={ }^{* * *}\right)$ and agility of LSSCs $(\beta=0.489$, $\mathrm{t}=5.105, p={ }^{* * *}$ ) confirmed a positive influence on performance, and integration abilities had a significant positive effect on the agility of LSSCs $\left(\beta=0.768, \mathrm{t}=8.413, p={ }^{* * *}\right)$. Thus, H6, H7 and H8 were supported. The path 'information sharing $\rightarrow$ agility of LSSCs' was insignificant at $p<0.05$. Therefore, $\mathrm{H} 3$ was not supported.

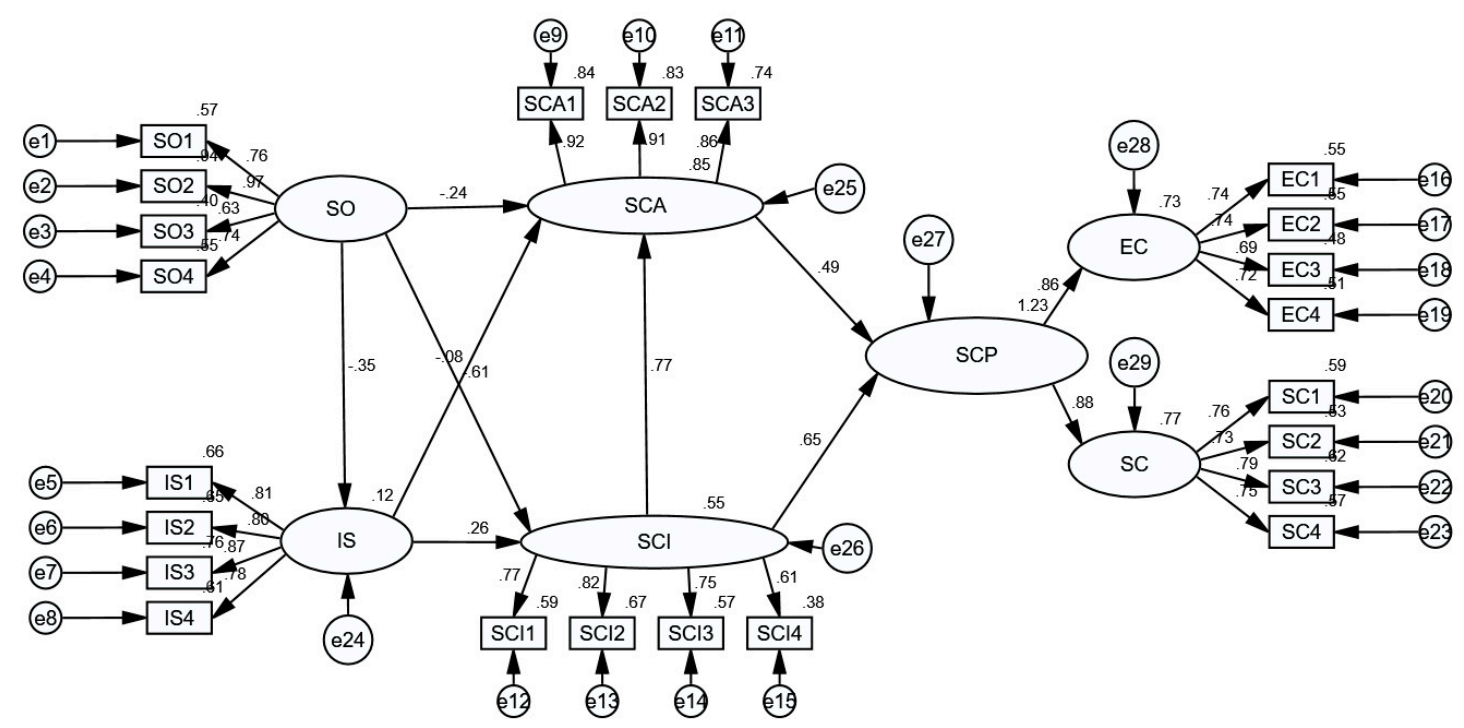

Figure 2. Diagram of the structural equation model.

Table 5. Hypothesis results for the structural model.

\begin{tabular}{ccccccc}
\hline $\begin{array}{c}\text { Path } \\
\text { Correlation }\end{array}$ & $\begin{array}{c}\text { Standardised } \\
\text { Path Coefficient }\end{array}$ & SE & CR & $p$ & Hypothesis & Results \\
\hline $\mathrm{IS} \leftarrow \mathrm{SO}$ & -0.348 & 0.057 & -5.082 & $* * *$ & H1 & Supported \\
\hline $\mathrm{SCI} \leftarrow \mathrm{IS}$ & 0.263 & 0.053 & 4.345 & $* * *$ & H5 & Supported \\
\hline $\mathrm{SCI} \leftarrow \mathrm{SO}$ & -0.609 & 0.056 & -7.806 & $* * *$ & H4 & Supported \\
\hline $\mathrm{SCA} \leftarrow \mathrm{SO}$ & -0.244 & 0.063 & -4.164 & $* * *$ & H2 & Supported \\
\hline $\mathrm{SCA} \leftarrow \mathrm{SCI}$ & 0.768 & 0.135 & 8.413 & $* * *$ & H6 & Supported \\
\hline $\mathrm{SCA} \leftarrow \mathrm{IS}$ & -0.076 & 0.056 & -1.729 & 0.084 & H3 & Not \\
\hline $\mathrm{SCP} \leftarrow \mathrm{SCA}$ & 0.489 & 0.071 & 5.105 & $* * *$ & H7 & Supported \\
\hline $\mathrm{SCP} \leftarrow \mathrm{SCI}$ & 0.646 & 0.027 & 5.600 & $* * *$ & H8 & Supported \\
\hline & & Note: ${ }^{*} p<0.05 ; * * 0.01 ; * * *<0.001$. & &
\end{tabular}

In addition, as shown by Figure 2, the interactions between integrator's opportunistic behavior and integration capabilities of LSSCs and between agility and performance of LSSCs have significant direct effects and indirect effects. Amongst them, information sharing may have a certain mediating 
effect on the interaction between integrator's opportunistic behavior and integration capabilities of LSSCs. The agility of LSSCs may likewise have a certain mediating effect on the relationship between integration capabilities and performance of LSSCs. To further explore the above findings, the possible mediating effects were also analyzed.

\subsection{Indirect Effect Path Test}

With regard to the mediation of interactions, some scholars have used the stepwise test method, which was initially proposed by Baron and Kenny [71], to set coefficient $\mathrm{c}$ as a precondition of the mediation effect. However, the use of this method has been questioned by many scholars because of several limitations. Different from previous ones, the present study used the bootstrap method for the product of coefficients [72]. The mediation effects of information-sharing behavior on the path 'integrator's opportunistic behavior $\rightarrow$ integration capability of LSSCs' and agility of LSSCs in the path 'integration capabilities of LSSCs $\rightarrow$ performance of LSSCs' were tested. Table 6 presents the bootstrap test results.

Table 6. Mediation effect for the structural model.

\begin{tabular}{|c|c|c|c|c|c|c|c|c|c|}
\hline \multirow{3}{*}{ Variable } & \multirow{3}{*}{$\begin{array}{l}\text { Point } \\
\text { Estimation }\end{array}$} & \multirow{2}{*}{\multicolumn{2}{|c|}{$\begin{array}{l}\text { Product of } \\
\text { Coefficients }\end{array}$}} & \multicolumn{4}{|c|}{ Bootstrapping } & \multirow{2}{*}{\multicolumn{2}{|c|}{$\begin{array}{c}\text { MacKinnon PRODCLIN2 } \\
95 \% \text { CI }\end{array}$}} \\
\hline & & & & \multicolumn{2}{|c|}{ Bias-Corrected $95 \%$ CI } & \multicolumn{2}{|c|}{ Percentile 95\% CI } & & \\
\hline & & SE & $\mathrm{Z}$ & Lower & Upper & Lower & Upper & Lower & Upper \\
\hline \multicolumn{10}{|c|}{ Indirect Effects } \\
\hline $\mathrm{SCI} \leftarrow \mathrm{SO}$ & -0.178 & 0.05 & -3.558 & -0.713 & -0.518 & -0.717 & -0.524 & -0.131 & -0.028 \\
\hline \multicolumn{10}{|c|}{ Indirect Effects } \\
\hline $\mathrm{SCP} \leftarrow \mathrm{SCI}$ & 0.470 & 0.138 & 3.406 & 0.474 & 0.944 & 0.486 & 0.966 & 0.226 & 0.773 \\
\hline
\end{tabular}

Note: $95 \%$ confidence, sample size 2000.

In the path of 'information sharing' as the mediation variable, results were as follows. (1) The indirect effect of opportunistic behavior on integration capabilities of LSSCs was estimated to be 3.558, a value greater than 1.96 (the critical value). (2) In addition, on the basis of the bias-corrected percentile method, percentile method and MacKinnon PRODCLIN2, the confidence intervals of the indirect effect were not 0 at the $95 \%$ confidence level, thus indicating a significant mediating effect. (3) According to Table 5, integrator's opportunistic behavior significantly and directly affects the integration capabilities of LSSCs. (4) Information sharing has a partial mediating effect on the interaction between integrator's opportunistic behavior and integration capabilities of LSSCs.

In the path of 'agility of LSSCs' as the mediation variable, results were as follows. (1) The indirect effect of integration capabilities on the performance of LSSCs was estimated to be 3.406, a value greater than 1.96 (the critical value). (2) In addition, on the basis of the bias-corrected percentile method, percentile method, and MacKinnon PRODCLIN2, the confidence intervals of the indirect effect were not 0 at the $95 \%$ confidence level, thus indicating a significant mediating effect. (3) According to Table 5, the integration capabilities of LSSCs significantly and directly affect the performance of LSSCs. (4) The agility of LSSCs has a partial mediating effect on the interaction between integration capabilities and performance of LSSCs.

\section{Discussion}

Integration capabilities of LSSCs were indicated to have the most significant determinant influencing performance of LSSCs, followed by agility of LSSCs. In addition, Integrator's opportunistic behavior has a direct negative impact on the agility and integration capabilities of LSSCs. Information sharing promotes the integration capabilities of LSSCs. However, Information sharing was affirmed to have no influence on the agility of LSSCs.

H3 was unexpectedly not supported. In a general product supply chain, information sharing exhibits a significantly positive influence on the agility of the supply chain. We conclude that this result may be due to China's advancement and the characteristics of the service supply chain which is 
different from a product supply chain. On the one hand, the integrated development of China's LSSCs remains in the initial stage and the degree of information sharing is relatively low [73]. Information sharing amongst partners must be recognized and learned by supply chain members before this activity can be transformed into an ability with agility. Thus, information sharing has been lagging behind [74]. On the other hand, the market volatility and substitutability of logistics services are high and are different from the stable partnership of product supply chain. Initial information sharing increases the workload of supply chain members and even affects the agility of LSSCs [75,76]. Information sharing amongst many partners does not translate into the agility of a supply chain, and the entire service supply chain collapses. Therefore, in an empirical measurement, H3 was not supported. To solve this problem, the most important thing is to maintain the stability of the LSSC relationship. On the one hand, integrators should improve the management ability of the whole supply chain and give them full trust. At the same time, the government can provide some policy benefits to the stable development of supply chain enterprises to encourage such behavior.

Information sharing partially intermediates the opportunistic behavior and integration capabilities of LSSCs. This conclusion is consistent with previous research results. In other words, the opportunistic behavior of integrators not only has a direct negative effect on performance of LSSCs but also negatively impacts the integration capability of the entire supply chain by reducing information sharing and creating information barriers amongst partners. Logistics service integrators often collaborate with multiple functional logistics service providers, and these integrators are regarded as the core leaders of their respective LSSCs. Nowadays, competition among enterprises has gradually changed into competition among supply chains. The effectiveness and diversity of information is the greatest advantage of supply chain. When initiated by integrators, high levels of information significantly and positively impact the cooperation of partners in the LSSC [77]. Such a scheme also helps accelerate information flow amongst service providers; promotes trust, stability and integration of relationships; improves the operational efficiency of the entire service supply chain; lowers overall operating cost; and increases customer satisfaction. Integrators should pay close attention to information sharing, particularly the speed and quality of information transmission amongst service providers, and promptly deliver available information to partners.

The agility of LSSCs partially intermediates the integration capabilities and performance of LSSCs. This conclusion is the same as our expectation. Specifically, the integration capability of supply chains not only directly improves performance but also improves the agility and rapid response capability of the supply chain. Ensuring the sustainable development of LSSCs is the common goal of supply chain members. The empirical results presented in this paper show that an LSSC's node of enterprises can improve the integration capability of the entire supply chain under the guidance of integrators, thereby ensuring rapid response against market fluctuations. When all members fully digest the shared information, the integration ability will improve the sensitivity of the supply chain. This outcome requires integrators to enhance their willingness to share information, improve the sense of security and belongingness of logistics service providers, maintain mutual trust amongst members and build stable partnerships from a strategic perspective.

When integrators manifest opportunistic behavior for their own interest, they also hinder information sharing and subsequently negatively affect the agility and integration capability of the supply chain. Opportunistic behavior should be limited in order to ensure the sustainability of supply chain performance. Assuming that integrators learn about the harm caused by their opportunistic speculations, they should then adopt a cautious attitude when selecting functional providers [78], carefully study and verify the business capabilities and organizational relationships of providers and strive to establish relationships based on cooperation and trust. Similarly, integrators can impose penalties for contract violations, fraud and similar acts of exploitation to constrain their own and their partners' opportunistic behavior. 


\section{Conclusion and Enlightenment}

Drawing upon behavioral science theory and Supply Chain effectiveness theory, this study develops a research model to examine the impact factors of the logistics service supply chain for sustainable performance. We conducted a survey in China and collected 271 valid data. We get the following unique findings: the impact of information sharing on the agility of service supply chain lags behind, and needs to be transformed into the integration capability of supply chain first. The results effectively illustrate the importance of continuous information sharing in LSSCs. Logistics enterprises should establish a solid strategic partnership and form an information sharing alliance. The agility and integration abilities of LSSCs, which are vulnerable to opportunistic behavior, are the key factors to improve the sustainability of supply chain performance. Integrators should have the willingness to improve their behavior and restrain opportunism. China's logistics industry is in the stage of transformation and upgrading. Based on the research results, we put forward management suggestions from the perspective of government and enterprises.

For enterprises, we have the following suggestions: (1) A reasonable cost distribution system must be established. Sustainable development and integration of logistics resources require enterprises to pay a certain cost in the short term. This cost must not be borne by several enterprises in the LSSC. Logistics service integrators, functional logistics service providers and customers in the supply chain must all bear an appropriate proportion of costs. Logistics service integrators that play a linking role in the supply chain must strengthen communication and in-depth cooperation with the upstream and downstream of the supply chain, establish a reasonable cost distribution system, coordinate the interests of all parties, and jointly overcome the cost barriers of the sustainable development of a supply chain. (2) A right partner must be selected. Service integrators must select the functional logistics service providers that conform to sustainable development norms when promoting a sustainable development strategy. The interests of enterprises in the supply chain are closely related. If the integrator makes mistakes in choosing the cooperative enterprise, it will directly affect the logistics service brand and cause irreparable losses. (3) A green operation must be realized from each logistics link. In the entire LSSC, the functional logistics service provider is the actual logistics activity operator. Functional logistics enterprises must actively adopt a sustainable development operation mode in procurement, transportation, storage, processing, and packaging. For example, an integrated transport system is adopted during transportation. A multi-modal transport method is skillfully applied by using unit loading and unloading as the carrier to improve transportation efficiency and reduce environmental pollution during transportation.

About government, some suggestions are put forward according to empirical analysis. (1) The government should issue relevant policies to encourage the integration of regional logistics resources. A single function and a small scale of functional logistics enterprises have determined that their enterprises exhibit special expertise in different regions or fields. During an operation, we must strengthen the integration of functional logistics enterprises, allow for the full play of the technical and cost advantages of different logistics service providers in their areas of expertise and achieve the maximum customer value with the lowest resource consumption. Thus, the total cost of logistics can be reduced and the sustainable profitability of logistics supply chain can be improved. (2) The government should promote the construction of logistics infrastructure. The government should give necessary financial support to the transportation, warehousing, distribution, information facilities, and park infrastructure construction of key logistics enterprises that meet the requirements. Traditional logistics parks are encouraged to transform and upgrade to informatization and integration.

This research has several limitations. Firstly, only the impact of the opportunistic behavior of integrators (i.e., the core players of LSSCs) on the performance of supply chains is discussed. Other impactful relationships may also exist amongst decentralized service providers. In addition, the study sample focused on the eastern part of China. Future studies can extend the sample size and investigate users from other countries, in order to obtain more reliable statistical analysis results and explore 
if there exist cultural differences. Finally, in different stages of the development of China's logistics industry, the factors affecting the performance of LSSCs will change, which needs continuous attention.

Author Contributions: Y.W. and Y.J. conceived of the study and completed the paper in English; Y.J. participated in data collection and drafted the article; Y.C. and J.J. revised the paper critically for important content.

Funding: This work was supported by the National Social Science Fund Project, China (grant number 17BJL055) and the Social Science Planning Research Project of Shandong, China (grant number 19BYSJ11).

Acknowledgments: The author would like to thank all those who participated in the interview and provided comments.

Conflicts of Interest: The authors declare no conflict of interest.

\section{References}

1. Gao, Y.; Chang, D.; Fang, T.; Luo, T. The Correlation between Logistics Industry and Other Industries: An Evaluation of the Empirical Evidence from China. Asian J. Shipp. Logist. 2018, 34, 27-32. [CrossRef]

2. Yu, M.; Fransoo, J.C.; Lee, C.-Y. Detention decisions for empty containers in the hinterland transportation system. Transp. Res. Part B-Methodol. 2018, 110, 188-208. [CrossRef]

3. Grunow, M.; Guenther, H.-O.; Pisinger, D. Logistics in supply chains (Part 2). Flex. Serv. Manuf. J. 2012, 24, 1-3. [CrossRef]

4. Shamsuzzoha, A.H.M.; Ehrs, M.; Addo-Tenkorang, R.; Duy, N.; Helo, P.T. Performance evaluation of tracking and tracing for logistics operations. Int. J. Shipp. Transp. Logist. 2013, 5, 31-54. [CrossRef]

5. Liu, W.-H.; Xu, X.-C.; Kouhpaenejad, A. Deterministic approach to the fairest revenue-sharing coefficient in logistics service supply chain under the stochastic demand condition. Comput. Ind. Eng. 2013, 66, 41-52. [CrossRef]

6. Rajahonka, M. Views of logistics service providers on modularity in logistics services. Int. J. Logist.-Res. Appl. 2013, 16, 34-50. [CrossRef]

7. Ekici, S.O.; Kabak, O.; Ulengin, F. Linking to compete: Logistics and global competitiveness interaction. Transp. Policy 2016, 48, 117-128. [CrossRef]

8. Sim, G. A Study on the Effects of Logistic Information System on Performance by Efficiency of Internal Operation and Organizational Innovation. J. Korea Port Econ. Assoc. 2008, 24, 85-102.

9. Altuntas, C.; Tuna, O. Greening Logistics Centers: The Evolution of Industrial Buying Criteria Towards Green. Asian J. Shipp. Logist. 2013, 29, 59-80. [CrossRef]

10. Chen, S.-H. The game analysis of negative externality of environmental logistics and governmental regulation. Int. J. Environ. Pollut. 2013, 51, 143-155. [CrossRef]

11. Ramamurthi, P.V.; Fernandes, M.C.; Nielsen, P.S.; Nunes, C.P. Logistics cost analysis of rice residues for second generation bioenergy production in Ghana. Bioresour. Technol. 2014, 173, 429-438. [CrossRef] [PubMed]

12. Thai, V.V. Logistics service quality: Conceptual model and empirical evidence. Int. J. Logist.-Res. Appl. 2013, 16, 114-131. [CrossRef]

13. Bae, H.S.; Ha, M. The Effect of Service Quality of Port Logistics Firms on Customer Satisfaction and Customer Loyalty of Korean Exporters. Korea Int. Commer. Rev. 2017, 32, 339-358.

14. Hassini, E.; Surti, C.; Searcy, C. A literature review and a case study of sustainable supply chains with a focus on metrics. Int. J. Prod. Econ. 2012, 140, 69-82. [CrossRef]

15. Shi, X.; Qian, Y.; Dong, C. Economic and Environmental Performance of Fashion Supply Chain: The Joint Effect of Power Structure and Sustainable Investment. Sustainability 2017, 9, 961. [CrossRef]

16. Solakivi, T.; Hofmann, E.; Toyli, J.; Ojala, L. The performance of logistics service providers and the logistics costs of shippers: A comparative study of Finland and Switzerland. Int. J. Logist.-Res. Appl. 2018, 21, 444-463. [CrossRef]

17. Park, J.H.; Gu, B.; Leung, A.C.M.; Konana, P. An investigation of information sharing and seeking behaviors in online investment communities. Comput. Hum. Behav. 2014, 31, 1-12. [CrossRef]

18. Huo, B.F.; Ye, Y.X.; Zhao, X.D.; Wei, J.; Hua, Z.S. Environmental uncertainty, specific assets, and opportunism in 3PL relationships: A transaction cost economics perspective. Int. J. Prod. Econ. 2018, 203, 154-163. [CrossRef] 
19. Yang, J. Supply chain agility: Securing performance for Chinese manufacturers. Int. J. Prod. Econ. 2014, 150, 104-113. [CrossRef]

20. Topal, B.; Sahin, H. The Influence of Information Sharing in the Supply Chain Process on Business Performance: An Empirical Study. Stud. Inform. Control 2018, 27, 201-212. [CrossRef]

21. Kang, G.-D. The Effects of Collaborative Communications, Relational Norms and Opportunistic Behaviors to Interorgnizational Relationship Performance: Focusing on the Moderating Effect of Uncertainty. Korean J. Bus. Adm. 2014, 27, 2181-2217.

22. Eckstein, D.; Goellner, M.; Blome, C.; Henke, M. The performance impact of supply chain agility and supply chain adaptability: The moderating effect of product complexity. Int. J. Prod. Res. 2015, 53, 3028-3046. [CrossRef]

23. Park, C.-K.; Kim, C.-B.; Park, S.-M. A Study on the Effect of Supply Chain Integration on Supply Chain Visibility and Supply Chain Performance. J. Bus. Res. 2018, 33, 21-49.

24. Yeongbok, S.E.O.; Park, C.-K. Effect of Supply Chain Integration on Real-Time Enterprise (RTE) Capabilities and Supply Chain Performance. J. SME Research 2017, 39, 55-78.

25. Sangari, M.S.; Razmi, J. Business intelligence competence, agile capabilities, and agile performance in supply chain: An empirical study. Int. J. Logist. Manag. 2015, 26, 356-380. [CrossRef]

26. Soni, G.; Kodali, R. Evaluating reliability and validity of lean, agile and leagile supply chain constructs in Indian manufacturing industry. Prod. Plan. Control 2012, 23, 864-884. [CrossRef]

27. Wu, I.-L.; Chuang, C.-H.; Hsu, C.-H. Information sharing and collaborative behaviors in enabling supply chain performance: A social exchange perspective. Int. J. Prod. Econ. 2014, 148, 122-132. [CrossRef]

28. Cheng, J.-H.; Sheu, J.-B. Inter-organizational relationships and strategy quality in green supply chains-Moderated by opportunistic behavior and dysfunctional conflict. Ind. Mark. Manag. 2012, 41, 563-572. [CrossRef]

29. Cortinhal, M.J.; Lopes, M.J.; Melo, M.T. Dynamic design and re-design of multi-echelon, multi-product logistics networks with outsourcing opportunities: A computational study. Comput. Ind. Eng. 2015, 90, 118-131. [CrossRef]

30. Yam, R.C.M.; Chan, C. Knowledge sharing, commitment and opportunism in new product development. Int. J. Oper. Prod. Manag. 2015, 35, 1056-1074. [CrossRef]

31. Yusuf, Y.Y.; Gunasekaran, A.; Musa, A.; Dauda, M.; El-Berishy, N.M.; Cang, S. A relational study of supply chain agility, competitiveness and business performance in the oil and gas industry. Int. J. Prod. Econ. 2014, 147, 531-543. [CrossRef]

32. Lee, C.B.; Yang, J. An Empirical Study on The Effects of Logistics Agility on the Business Performance. Korea Int. Commer. Rev. 2008, 23, 25-47.

33. Gimenez, C.; van der Vaart, T.; van Donk, D.P. Supply chain integration and performance: The moderating effect of supply complexity. Int. J. Oper. Prod. Manag. 2012, 32, 583-610. [CrossRef]

34. Kim, S. The Effects of Formulation and Implementation of Supply Chain Strategy on Collaboration Performance: Moderating Effects of Trust and Committment. Korean Corp. Manag. Rev. 2012, 19, 27-49.

35. Blome, C.; Schoenherr, T.; Eckstein, D. The impact of knowledge transfer and complexity on supply chain flexibility: A knowledge-based view. Int. J. Prod. Econ. 2014, 147, 307-316. [CrossRef]

36. Stank, T.; Brzica, M.; Ficenec, J. The benefits of supply chain integration using a third-party integrator. Transfusion 2009, 49 Pt 2, 2536-2538. [CrossRef]

37. Ganesh, M.; Raghunathan, S.; Rajendran, C. Distribution and Equitable Sharing of Value From Information Sharing Within Serial Supply Chains. IEEE Trans. Eng. Manag. 2014, 61, 225-236. [CrossRef]

38. Banyai, T. Real-Time Decision Making in First Mile and Last Mile Logistics: How Smart Scheduling Affects Energy Efficiency of Hyperconnected Supply Chain Solutions. Energies 2018, 11, 1833. [CrossRef]

39. Lin, Y.-T.; Chen, Y.-J. Competitive outsourcing: Choosing between value-added services and key component supplying capability. Int. J. Prod. Res. 2015, 53, 3635-3650. [CrossRef]

40. Liu, W.; Wang, D.; Shen, X.; Yan, X.; Wei, W. The impacts of distributional and peer-induced fairness concerns on the decision-making of order allocation in logistics service supply chain. Transp. Res. Pt. e-Logist. Transp. Rev. 2018, 116, 102-122. [CrossRef]

41. Xue, Y.; Ge, L. Cost Optimization Control of Logistics Service Supply Chain Based on Cloud Genetic Algorithm. Wirel. Person. Commun. 2018, 102, 3171-3186. [CrossRef] 
42. Huemer, L. Unchained from the chain: Supply management from a logistics service provider perspective. J. Bus. Res. 2012, 65, 258-264. [CrossRef]

43. Liu, W.; Zhao, X.; Wu, R. Revenue-Sharing Contract Models for Logistics Service Supply Chains with Mass Customization Service. Math. Probl. Eng. 2015, 2015, 572624. [CrossRef]

44. Liu, W.; Xie, D.; Xu, X.-c. Quality supervision and coordination of logistic service supply chain under multi-period conditions. Int. J. Prod. Econ. 2013, 142, 353-361. [CrossRef]

45. Wang, W.J.; Xu, Q. A Bayesian Combination Forecasting Model for Retail Supply Chain Coordination. J. Appl. Res. Technol. 2014, 12, 315-324. [CrossRef]

46. Jonsson, P.; Rudberg, M.; Holmberg, S. Centralised supply chain planning at IKEA. Supp. Chain Manag. Int. J. 2013, 18, 337-350. [CrossRef]

47. Nav, H.N.; Motlagh, M.R.J.; Makui, A. Robust controlling of chaotic behavior in supply chain networks. J. Oper. Res. Soc. 2017, 68, 711-724.

48. Hyun, M.-C.; Cho, B.-Y. The Risk Management in Supply Chain Management and the Firm Performance: Suppliers' Perspective. J. Prod. Res. 2018, 36, 75-86.

49. Chae, B.; Olson, D.; Sheu, C. The impact of supply chain analytics on operational performance: A resource-based view. Int. J. Prod. Res. 2014, 52, 4695-4710. [CrossRef]

50. Jajja, M.S.S.; Chatha, K.A.; Farooq, S. Impact of supply chain risk on agility performance: Mediating role of supply chain integration. Int. J. Prod. Econ. 2018, 205, 118-138. [CrossRef]

51. Wang, Z.; Ye, F.; Tan, K.H. Effects of managerial ties and trust on supply chain information sharing and supplier opportunism. Int. J. Prod. Res. 2014, 52, 7046-7061. [CrossRef]

52. Kim, C.-B.; Park, C.-K. A Study on Supply Chain Integration and Corporate \& Supply Chain Performances in Terms of Development Chains. J. Korean Soc. Supp. Chain Manag. 2016, 16, 105-122.

53. Gligor, D.M.; Holcomb, M.C.; Stank, T.P. A Multidisciplinary Approach to Supply Chain Agility: Conceptualization and Scale Development. J. Bus. Logist. 2013, 34, 94-108. [CrossRef]

54. Fayezi, S.; Zomorrodi, M. The role of relationship integration in supply chain agility and flexibility development An Australian perspective. J. Manuf. Technol. Manag. 2015, 26, 1126-1157. [CrossRef]

55. Qi, Y.N.; Huo, B.F.; Wang, Z.Q.; Yeung, H.Y.J. The impact of operations and supply chain strategies on integration and performance. Int. J. Prod. Econ. 2017, 185, 162-174. [CrossRef]

56. Wong, C.W.Y.; Lai, K.-h.; Bernroider, E.W.N. The performance of contingencies of supply chain information integration: The roles of product and market complexity. Int. J. Prod. Econ. 2015, 165, 1-11. [CrossRef]

57. Alfalla-Luque, R.; Marin-Garcia, J.A.; Medina-Lopez, C. An analysis of the direct and mediated effects of employee commitment and supply chain integration on organisational performance. Int. J. Prod. Econ. 2015, 162, 242-257. [CrossRef]

58. Tarafdar, M.; Qrunfleh, S. Agile supply chain strategy and supply chain performance: Complementary roles of supply chain practices and information systems capability for agility. Int. J. Prod. Res. 2017, 55, 925-938. [CrossRef]

59. Anderson, E. Transaction costs as determinants of opportunism in integrated and independent sales forces. J. Econ. Behav. Org. 1988, 9, 247-264. [CrossRef]

60. Rokkan, A.I.; Heide, J.B.; Wathne, K.H. Specific Investments in Marketing Relationships: Expropriation and Bonding Effects. J. Mark. Res. 2003, 40, 210-224. [CrossRef]

61. Zhou, H.; Benton, W.C., Jr. Supply chain practice and information sharing. J. Oper. Manag. 2007, 25, 1348-1365. [CrossRef]

62. Ye Fei, Z.J. Lv Hui, Research on the Impact of Supplier Opportunism on Information Sharing and Operational Performance. J. Manag. Sci. 2012, 25, 51-60.

63. Patricia, M.; Swafford, S.G.; Murthy, N. Achieving Supply Chain Agility through IT Integration and Flexibility. Int. J. Prod. Econ. 2008, 116, 288-297.

64. Flynn, B.B.; Huo, B.; Zhao, X. The impact of supply chain integration on performance: A contingency and configuration approach. J. Oper. Manag. 2010, 28, 58-71. [CrossRef]

65. Peng, J.; Jie, D. Extension Goodness Evaluation on Performance Index of BSC-Based Logistics Service Supply Chain. Stat. Decis. 2018, 34, 44-48.

66. Feng, C.; Zhang, M.; Liu, H.; Zhang, H.; He, M. Research on the Relationship between Supply Chain Knowledge Sharing and Firm Performance: The Mediating and Moderating Effect of Supply Chain Agility and Environmental Dynamics. Manag. Rev. 2015, 27, 181-191. 
67. Thompson, B. Exploratory and Confirmatory Factor Analysis: Understanding Concepts and Applications. Appl. Psychol. Meas. 2017, 31, 245-248.

68. Nunnally, J.C. Psychometric theory. Am. Educ. Res. J. 1978, 5, 83.

69. Bagozzi, R.P. Evaluating Structural Equation Models with Unobservable Variables and Measurement Error: A Comment. J. Mark. Res. 1981, 18, 375-381. [CrossRef]

70. Jackson, D.L.; J Arthur, G.; Rebecca, P.S. Reporting practices in confirmatory factor analysis: An overview and some recommendations. Psychol. Methods 2009, 14, 6-23. [CrossRef]

71. Baron, R.M.; Kenny, D.A. The Moderator-Mediator Variable Distinction in Social Psychological Research: Concept Strategic and Statistical Considerations. J. Personal. Soc. Psychol. 1986, 51, 1173-1182. [CrossRef]

72. Taylor, A.B. MacKinnon, D.P. and Tein, J.-Y. Tests of the Three-Path Mediated Effect. Organ. Res. Methods 2008, 11, 241-269. [CrossRef]

73. Jakhar, S.K.; Barua, M.K. An integrated model of supply chain performance evaluation and decision-making using structural equation modelling and fuzzy AHP. Prod. Plan. Control 2014, 25, 938-957. [CrossRef]

74. Liu, C.; Huo, B.; Liu, S.; Zhao, X. Effect of information sharing and process coordination on logistics outsourcing. Ind. Manag. Data Syst. 2015, 115, 41-63. [CrossRef]

75. Spillan, J.E.; McGinnis, M.A.; Kara, A.; Yi, G.L. A comparison of the effect of logistic strategy and logistics integration on firm competitiveness in the USA and China. Int. J. Logist. Manag. 2013, 24, 153-179. [CrossRef]

76. Jang, H.M.; Marlow, P.B.; Mitroussi, K. The Effect of Logistics Service Quality on Customer Loyalty through Relationship Quality in the Container Shipping Context. Transp. J. 2013, 52, 493-521. [CrossRef]

77. Ahmad, N.; Mehmood, R. Enterprise systems and performance of future city logistics. Prod. Plan. Control 2016, 27, 500-513. [CrossRef]

78. Liu, C.-L.; Lai, P.-Y. Impact of external integration capabilities of third-party logistics providers on their financial performance. Int. J. Logist. Manag. 2016, 27, 263-283. [CrossRef]

(C) 2019 by the authors. Licensee MDPI, Basel, Switzerland. This article is an open access article distributed under the terms and conditions of the Creative Commons Attribution (CC BY) license (http://creativecommons.org/licenses/by/4.0/). 